\title{
KEUDUKAN PEREMPUAN MINANGKABAU DALAM PERSPEKTIF GENDER
}

\author{
Oleh: \\ Silmi Novita Nurman \\ silminovita119@yahoo.com
}

\begin{abstract}
Abstrak
Tulisan ini mengkaji bagaimana kedudukan perempuan Minangkabau dalam perspektif gender. Perempuan Minangkabau memiliki kedudukan yang sangat istimewa yaitu sebagai bundo kanduang atau dalam istilah adat: limpapeh ruumah nan gadang. Karena perempuan memiliki kuasa maka ia memiliki peran yang sama dengan laki-laki termasuk pengambilan keputusan dalam keluarga. Namun, hal tersebut berlaku ketika dia sudah menikah, sudah mejadi istri atau ibu, selagi ia masih gadis, maka ia diatur oleh laki-laki yaitu mamak. Demikian juga dalam pola mengurus anak. Dalam mengurus anak, perempuan memiliki peran yang penting, tetapi berbanding terbalik dengan ayah bahkan hampir tidak memiliki peran sama sekali. Dan sebagai bundo kanduang, perempuan Minangkabau memiliki keterlibatan dalam menyelesaikan segala persoalan yang ada dalam masyarakat, jika tidak kata bundo kanduang, maka keputusan tidak dapat disahkan.
\end{abstract}

Kata kunci: Perempuan, Gender, Adat Istiadat Minangkabau

\section{A. Pendahuluan}

Menyoal tentang perempuan, maka hal pertama yang menjadi pertanyaan adalah: apakah perempuan itu? Seorang bijak berusaha untuk menjawabnya "Tota mulier in utero", perempuan adalah rahim; memiliki indung telur, ia betina. Secara sederhana, mungkin pemaknaan itu telah dapat menjawab pertanyaan. Lantas, apalagi masalahnya? Suatu permasalahan dianggap masalah jika orang yang mempermasalahkan menganggap hal tersebut adalah masalah. Mengingat bahwa ada perempuan yang merasa tidak ada masalah sedikit pun dari dirinya yaitu diri yang disebut sebagai perempuan karena secara kodrat, ia memiliki sel telur, rahim, melahirkan dan menyusui, tetapi hal demikian tidak dimiliki oleh laki-laki. Namun, di lain pihak, ada perempuan yang ia menerima sesuatu yang bersifat kodrati tersebut, tetapi juga gelisah dengan segala 
ketimpangan dan perbedaan dengan laki-laki di tengah-tengah kehidupan sosial yaitu adanya perbedaan gender (gender differences) baik di ranah publik maupun domestik.

Atas dasar itu, tulisan ini penting dilakukan pengkajian lebih lanjut untuk menelaah lebih lanjut terkait sejauh mana kedudukan perempuan Minangkabau, apakah ia memiliki peran yang sama dengan lakilaki, apakah ketika pengambilan kepuusan suaranya didengar serta sejauh mana keterlibatan perempuan dalam menyelesaikan persoalan yang ada dalam rumah gadang pun dalam masyarakat.

\section{B. Sekilas Tentang Gender}

Konsep tentang gender itu sendiri masih berada pada ranah abuabu, ranah perdebatan, mengingat kata gender dalam bahasa Indonesia sendiri dipinjam dari bahasa Inggris dan di kamus pun tidak secara terang dibedakan pengertian kata sex dan gender. Di lain pihak, belum ada uraian yang mampu menjelaskan secara singkat dan jelas mengenai konsep gender dan mengapa konsep tersebut digunakan untuk memahami sistem ketidakadilan sosial.

Gender berasal dari bahasa Inggris; gender. Menurut Oxford Advanced Learner's Dictionary, adalah: "the facts of being male or female especially when considered with reference to social and culture differences in biology (A.S Hornby, Oxford Advanced Learner's Dictionary, 2012: 622), yaitu perbedaan yang tampak pada laki-laki atau perempuan sebagai hasil konstruk sosial dan budaya, bukan berdasarkan perbedaan jenis kelamin. Pandangan ini sejalan dengan E.F dan Montgomery bahwa gender ditetapkan berdasarkan prilaku, peran sosial dan ukuran lain selain jenis kelamin. Maksudnya, dalam menentukan laki-laki dan perempuan tidak dapat dilihat berdasarkan jenis kelamin namun harus dilihat berdasarkan aspek sosial dan karakter dari seseorang (Borgatta, E.F dan Montgomery, R.J.V, Encyclopedia of Sociology, Vol 2, 2000: 1057). Di lain pihak, Graham dan Joan Wallach justru memberikan pengertian sebaliknya bahwa gender lebih menekankan pada perbedaan jenis kelamin biologis yang menentukan pembagian sosial antara laki-laki dan perempuan. $^{1}$

Menurut Mansour Fakih, untuk memahami konsep gender harus dibedakan kata gender dengan kata seks (jenis kelamin), sebab dua kata ini sama sekali berbeda. Seks atau jenis kelamin merupakan pensifatan atau pembagian dua jenis kelamin manusia yang ditentukan secara biologis yang melekat pada jenis kelamin tertentu. Misalnya manusia jenis laki-laki adalah manusia yang memiliki penis, memproduksi sperma. Sedangkan jenis perempuan memiliki alat reproduksi seperti rahim dan saluran untuk melahirkan, memproduksi telur, memiliki vagina dan mempunyai alat menyusui. Alat-alat tersebut secara biologis melekat pada manusia jenis perempuan dan laki-laki selamanya. Artinya alat tersebut tidak bisa dipertukarkan. Secara permanen tidak

\footnotetext{
${ }^{1}$ Lihat Graham, "Making Difference" dalam Franzmann Magazine, "Woman and Religion", (2000), 6. Lihat juga Joanne Meyerowitz, "A History of Gender" dalam The American Historical Review, Vol 113, No 5, December, (USA: University of Chicago Press, 2008), 1355.
} 
berubah dan ketentuan biologis sudah menjadi ketentuan atau kodrat Tuhan (Mansour Fakih, Analisis Gender dan Transformasi Sosial, 2013: 7-8)..

Sejalan dengan itu, bagi Simone de Beauvoir, pembagian jenis kelamin merupakan fakta biologis, bukan merupakan fakta sejarah. Lakilaki dan perempuan bertentangan dalam Mitsein primordial dan perempuan tidak mampu menghancurkannya. Dengan adanya pasangan yang merupakan suatu kesatuan fundamental yang dipancangkan bersama, pemisahan masyarakat atas dasar jenis kelamin menjadi mustahil (Simone de Beauvoir, Second Sex: Fakta dan Mitos terj. Toni B. Febriantono, xvii). Dari sini, lanjut Simone, terlihat ciri dasar perempuan: ia adalah "sosok yang lain" dalam sebuah totalitas di mana kedua komponen tersebut saling membutuhkan.

Sedangkan konsep gender adalah suatu sifat yang melekat pada kaum laki-laki maupun perempuan yang dikonstruksi secara sosial maupun kultural. Misalnya, perempuan atau disebut dengan istilah feminin dikenal lemah lembut, cantik, emosional atau keibuan. Sementara laki-laki (maskulin) dianggap kuat, rasional, jantan, perkasa. Ciri dari sifat-sifat tersebut merupakan sesuatu yang dapat dipertukarkan. Sejarah perbedaan gender (gender differences) antara manusia jenis kelamin laki-laki dan perempuan terjadi melalui proses yang sangat panjang. Oleh karena itu, terbentuknya perbedaan gender disebabkan banyak faktor, diantaranya dibentuk, disosialisasikan, diperkuat bahkan dikonstruksi secara sosial atau kultural melalui ajaran agama dan negara. Melalui proses panjang itu, sosialisasi gender akhirnya dianggap menjadi ketentuan Tuhan seolah-olah bersifat biologis yang tidak bisa diubah lagi sehingga perbedaan-perbedaan gender dianggap dan dipahami sebagai kodrat laki-laki dan kodrat perempuan (Mansour Fakih, Analisis Gender dan Transformasi Sosial,: 8-9). Dari perbedaan pandangan ini setidaknya menjadi gambaran bahwa istilah gender dari pengusungnya sendiri tidak memiliki makna yang pasti.

Pengistilahan maskulin dan feminin digunakan secara simetris semata-mata sebagai masalah bentuk, layaknya kertas-kertas resmi. Dalam aktualnya, hubungan kedua jenis kelamin ini tidak persis seperti dua arus listrik, karena laki-laki mewakili baik arus positif dan arus netral, sebagaimana diindikasikan dengan pemakaian kata laki-laki untuk menunjukkan umat manusia secara umum; sementara perempuan hanya mewakili hal-hal yang berkonotasi negatif yang didefinisikan oleh kriteriakriteria terbatas tanpa adanya hubungan timbal balik (Simone, Second Sex, 2016: vi-vii). Dengan demikian, Laki-laki merasa superior dibandingkan perempuan. Maka tak heran Aristoteles menyebut perempuan dengan sifat khusus yang kurang berkualitas, di mana harus dipandang sebagai suatu ketidaksempurnaan alam. Hal tersebut tentu mengindikasikan bahwa perempuan adalah makhluk inferior yang terpinggirkan. Meskipun gender tidak memiliki definisi yang pasti, namun dalam pergerakannya makna gender dalam jenis kelamin sosial lebih sering digunakan.

\section{Adat Istiadat Minangkabau}


Adat Minangkabau adalah salah satu adat yang unik di Indonesia, terlebih masyarakatnya menganut sistem matrilineal. Sama dengan daerah-daerah lain, Minangkabau juga memiliki adat istiadat yang mengatur tatanan masyarakatnya baik secara individu, kelompok maupun sosial. Tatanan yang telah diatur tersebut yang kemudian menjadi pegangan hidup (way of life) masyarakat Minangkabau. Mengutip A.A Navis, adat adalah kebudayaan secara utuh yang dapat berubah. Namun ada adat yang tidak dapat berubah, seperti kata mamangan: kain dipakai usah, adaik dipakai baru (kain dipakai usang, adat dipakai baru) (A.A Navis, Alam Terkembang Jadi Guru: Adat dan Kebudayaan Minangkabau, 1982: 88-89). Maksudnya, sebagaimana pakaian apabila dipakai terus akan usang, sedangkan adat yang dipakai terusmenerus akan senantiasa awet. Oleh karena itu, di Minangkabau, ada adat yang tetap tidak berubah dan ada adat yang berubah, maka adat tersebut dibagi menjadi empat karegori: adat yang sebenar adat, adat istiadat, adat yang diadatkan, dan adat yang teradat.

Pertama, adat yang sebenar adat. Adat yang sebenar adat adalah adat yang asli, tidak berubah, tak lapuk oleh hujan tak lapuk oleh panas. Kalau dipaksa dengan keras mengubahnya, ia dicabuik indak mati, diasak indak layиa (dicabut tidak mati, dipindahkan tidak layu). Adat yang lazim diungkapkan dalam pepatah ini seperti hukum alam yang merupakan falsafah hidup orang Minangkabau sendiri.

Kedua, adat istiadat. Yang dimaksud dengan adat istiadat adalah kebiasaan yang berlaku di tengah masyarakat setempat, seperti acara seremoni atau tingkah laku pargaulan yang apabila dilakukan dianggap baik dan bila tidak dilakukan tidak apa-apa. Adat ini dalam mamangan diibaratkan: pohon sayuran yang gadang diambak, tinggi dek dianjuang (besar karena dilambuk, tinggi karena dianjung). Artinya, adat akan tetap tumbuh karena dirawat dengan baik.

Ketiga, adat yang diadatkan. Maksud dari adat ini adalah apa yang dinamakan sebagai undang-undang dan hukum yang berlaku, seperti yang didapati pada Undang-undang Luhak dan rantau, Undang-undang nan Duo Puluah. Mamangan terhadap adat ini: jikok dicabuik mati, jikok diasak layua (jika dicabut mati, jika dipindahkan layu), ibarat pohon yang hidup tumbuh berakar yang tumbuh apabila tidak ada tangan yang mengganggu.

Keempat, adat yang teradat. Maksudnya adalah peraturan yang dilahirkan oleh mufakat atau konsensus masyarakat yang memakainya, seperti kata mamangan: patah tumbuah hilang baganti (patah tumbuh, hilang berganti). Ibarat pohon yang patah karena bencana, maka ia akan dapat tumbuh lagi pada bekas patahannya. Kalai ia hilang, ia diganti pohon lain pada bekas tempatnya hilang karena pohon perlu ada untuk keberlangsungan hidup manusia. ${ }^{2}$

Di lain pihak, seperti kata Taufik Abdullah, sebagaimana kata pepatah: adat hanyalah selingkung aur. Maksudnya, dalam realitas hidup sehari-hari, setiap nagari di Minangkabau mempunyai adat dan

\footnotetext{
2 Artinya diperlukannya pemimpin untuk memimpin jalannya roda pemerintahan agar adat di Minangkabau tetap dilanggengkan. Lihat A.A Navis, Alam Terkembang Jadi Guru, 89.
} 
kebiasaan yang berbeda-beda, tetapi realitas bisa menjaga diri sendiri. Yang utama adalah bagaimana adat sebagai kerangka konseptual, bukan sebagai aktualitas harus dirumuskan. Misalnya, tahun 1875 hak penghulu dan balai adat untuk mengadili masalah pidana dihapuskan oleh pemerintah kolonial. Akan tetapi, kenyataan tersebut tidak mengurangi keharusan untuk mengetahui dan mendalami prinsipprinsip hukum pidana dalam adat Minangkabau. Hakikatnya, bukan keberlakuannya yang terpenting, namun cara adat untuk memelihara dan menyelesaikan berbagai bentuk perbuatan yang mengganggu ketentraman sosial. ${ }^{3}$ Klasifikasi adat di atas adalah sebagai positioning pegangan untuk menuntun masyarakat Minangkabau dalam bertindak, termasuk pegangan bagi perempuan Minangkabau, mengingat perempuan di Minangkabau disebut sebagai bundo kanduang: limpapeh rumah gadang.

\section{Perempuan Minangkabau}

Perempuan dalam bahasa Minangkabau disebut padusi atau dalam bahasa Indonesia, perempuan. Di Minangkabau, perempuan mendapat porsi dan posisi yang sangat istimewa karena segala keputusan berada di tangannya. Semacam relasi kuasa, tanpa adanya kata boleh dari perempuan, maka segala rencana belum dapat dilaksanakan pengerjaannya. Perempuan Minangkabau juga disebut sebagai bundo kanduang yang secara harfiah diartikan sebagai ibunda atau ibu

\footnotetext{
${ }^{3}$ Ph.S. Van Ronkel, "De invoering van ons Strafwetboek ter SWK naar aanteekeningen in een Maleische Handschrift”, TBB. 46 (1994), 249-255 lihat dalam A.A Navis, Alam Terkembang Jadi Guru, xvii-xviii.
}

kandung. Ada banyak arti terkait pemaknaan bundo kanduang, yang jelas, secara sederhana, bundo kanduang adalah seorang pemimpin non formal bagi seluruh perempuan dan anak cucunya dalanm suatu kaum. Kepemimpinan tersebut tumbuh atas kemampuan dan kharismanya sendiri yang didukung dan diakui oleh anggota-anggota kaumnya (Ibrahim Dt. Sanggoeno Diradjo, Tambo Alam Minangkabau: 346). Maka, tak heran perempuan Minangkabau itu sangat terhormat. Ia memiliki grand position yang sangat bagus dalam kaumnya.

Kedudukan tertinggi perempuan Minangkabau adalah bundo kanduang. Adanya bundo kanduang dalam suatu kaum karena kaum memerlukan seorang pemimpin perempuan yang dapat memimpin seluruh perempuan beserta anak cucu yang ada dalam kaum. Dengan demikian, setiap perempuan Minangkabau harus terdidik dan berpendidikan ibaratnya tau alua jo patuik, tau rantiang nan kamancucuak, alun takilek lah takalam. Secara tidak langsung, ini sejalan dengan apa yang tengah digaungkan jamak orang sekarang yaitu terkait kesetaraan gender. Bahkan, sebelum isu kesetaraan gender itu bergema di seluruh jagad bumi, terutama di dunia Barat, orang Minangkabau telah menjalankan apa yang disebut sebagai kesetaraan gender tersebut.

Berdasarkan adat bersendi syarak, syarak bersendi kitabullah, peran bundo kanduang adalah; pertama, sebagai urang rumah (pemilik rumah) . artinya, orang Minangkabau harus selalu memiliki rumah dan tanah kuburan milik keluarga. Kedua, sebagai induak bareh (nan lamah ditueh 
nan condong ditungkek, ayam barinduak, siriah bajunjuang). artinya ibu rumah tangga yang mengatur makanan dan minuman seluruh keluarga besar, yang miskin dibantu yang besar diajak bicara. Ketiga, sebagai pemimpin yaitu perempuan Minangkabau sangat arif. Kearifan adalah menjadi asas utama bagi kepemimpinan di tengah masyarakat.

\section{Menurut Ibrahim Dt.} Sanggoeno Diradjo dalam Tambo Alam Minangkabau, ${ }^{4}$ padusi atau perempuan jika dilihat dari prilaku dan perbuatannya diklasifikasikan kepada tiga sebutan, yaitu:

Pertama, Simarewan. Dalam titah adat Minangkabau, padusi Simarewan ini sebagai: "mano nan padusi simarewan, bapaham sarupo gatah cayia, iko elok itu katuju, bak cando pimpiang di lereang, baparangai sarupo pucuak aru, ka mano angin inyo ka kian, alun dijujai inyo lah galak, alun diimbau inyo lah datang..." Padusi Simarewan memiliki sifat yang negatif yaitu disifati sebagai orang yang tidak mempunyai pendirian, mudah digoda dan dirayu, mudah didekati laki-laki, terlampau lincah dan genit, banyak ketawa daripada bicara, kurang sopan dan tidak punya malu. Oleh sebab itu,

\footnotetext{
4 Tambo dalam budaya Minangkabau adalah sejenis kitab tarikh atau sejarah yang merekam kisah-kisah dan legenda-legenda terkait tradisi dan alam Minangkabau. Dari Tambo itu diperoleh informasi, yaitu tentang asal usul lahirnya kehidupan berkeluarga di Minangkabau, dimulai dari kedatangn ninik moyang Minangkabau Sri Maharaja Diraja bersama para pengikutnya dari kasta Cateri. Lihat Ibrahim Dt. Sanggoeno Diradjo, Tambo Alam Minangkabau: Tatanan Adat Warisan Nenen Moyang Orang Minang (Bukittinggi: Kristal Multimedia, 2009), 272-282 dan 374.
}

perempuan ini disebut sebagai Simarewan karena prilakunya jelek dan tidak menampakkan diri sebagai perempuan Minangkabau.

Kedua, Mambang Tali Awan. Dalam titah adat: "kok dibincang si Mambang Tali Awan, kalau mangecek samo gadang, atau barundiang di nan rami, sagalo labiah dari urang, tasambia juo bapk si buyuang, basabuik juo bapak si upiak, nan sagalo labiah dari urang, baiak tantang pambalinyo, atau tantang kasiah sayangnyo, siang jo malam jarang di rumah, naiak rumah turun rumah..." Perempuan Mambang Tali Awan hampir sama dengan perempuan Simarewan bahwa ketika dalam berbicara dan berunding selalu menunjukkam bahwa dia lebih hebat dari yang lain termasuk suami, anak, menantu, saudara maupun karibkerabat. Selain itu, perempuan Mambang Tali Awan juga suka bertandang ke rumah orang, bergunjing, suka menyebut aib orang, suka duduk dipinggir jalan, berlagak mampu tapi sebaliknya, tidak bisa memasak pun kurang rasa malu dan sopan serta suka membuat keonaran di tengah masyarakat.

Ketiga, Perempuan. Perempuan atau padusi terbaik yang diingini dan sesuai dengan titah adat Minangkabau adalah parampuan atau perempuan, sebab perempuan mempunyai sifatsifat dan prilaku terpuji, baik budi pekerti dan tingkah laku maupun kecakapan, kemampuan dan ilmu pengetahuannya. Sifat-sifat dan prilaku perempuan tersebut dikatakan dalam titah adat yang berbunyi: "mano nan disabuik parampuan, mamakai taratik sarato sopan, nan mamakai baso jo basi, tau diereng saroto gendeng, 
mamakai raso jo pareso, manaruah malu sarato sopan, manjauahi sumbang sarato salah, muluik manih baso katuju, kato baiak kucindan murah..." Itulah klasifikasi perempuan menutut titah adat Minangkabau, di mana perempuan yang baik dan terbaik itu adalah parampuan atau perempuan mengingat ia adalah limpapeh rumah nan gadang sehingga dia harus memiliki laku dan perangai yang baik dan sopan.

Dari ketiga klasifikasi perempuan menurut adat tersebut, golongan simarewan dan mambang tali awan adalah golongan perempuan yang tidak diinginkan di Minangkabau. Hanya golongan perempuan atau parampuan, perempuan yang ideal menurut adat Minangkabau. Namun dalam pelaksanaannya, golongan perempuan tersebut secara garis besar hanya terdapat pada perempuan Minangkabau yang masih gadis. Ketika perempuan Minangkabau sudah menjadi istri dan ibu serta tinggal di rumah gadang, ia akan berada di bawah pengaruh dan tekanan Mamak Tungganai, Bundo Kanduang dan kaum saparuik-nya.

Namun, jika dilihat lebih jauh, secara kemerdekaan dan kebebasan, perempuan Minangkabau tidak pernah merdeka atau memiliki kebebasan dalam menentukan pilihan. Perempuan Minangkabau baru memperoleh kemerdekaan dalam menentukan pilihan dan pendapatnya bisa menjadi pertimbangan setelah perempuan Minangkabau mencapai kedudukan sebagai bundo kanduang. Artinya, selama belum mencapai kedudukan sebagai bundo kanduang, perempuan Minangkabau akan terus hidup di bawah pengaruh tekanan laki-laki yang menyandang sebutan mamam. Dalam perspektif gender, secara universal tentu dapat ditarik kesimpulan bahwa memang benar kedudukan perempuan Minangkabau mendapat posisi yang spesial, tapi keistimewaan itu tidak di dapat sejak lahir yang sudah bebas dengan segala pilihan dan tidak mendapat dikte dari laki-laki. Artinya, perempuan Minangkabau masih berada di bawah bayang-bayang patriaki, dalam hal ini mamak.

Secara ontologis, ada banyak laku atau perangai serta sifat yang baik bagi setiap perempuan Minangkabau, diantaranya: berhati sabar menurut titah dan nasehat suaminya, orangtuanya, dan ninik mamak serta sanak saudaranya. Lebih jauh, ia wajib memberi contoh teladan bagi anakanaknya sebagai penerus generasi dan pemuda harapan bangsa, sebab, parampuan Minangkabau memiliki tiga martabat yang wajib ia miliki dan terapkan di dalam kehidupan bermasyarakat, yaitu: memelihara malunya, teguh akan janjinya dan berilmu yang baik kepada Allah pun kepada segala makhluknya. Jika perempuan tidak punya malu. Tidak sopan, maka perempuan itu seperti gulai yang tak dikasih garam karena malu kulitnya iman, teguh janji kuat akalnya, baik secara lahir maupun batin. Apabila seorang perempuan tidak tetap akalnya, ia seperti perahu yang tak berkemudi akibatnya terombang-ambing di laut lepas. Teguh janji itulah yang dinamakan kemudi (Sanggoeno Diradjo, Tambo: 283).

Dengan adanya klasifikasi perempuan dalam adat Minangkabau di atas dapat menjadi world view terakait apa dan bagaiamana citra perempuan di Minangkabau bagi masyarakat pada 
umumnya. Tentu ini menjadi nilai tambah bagi perempuan Minangkabau agar orang di luar Minangkabau tahu sosok perempuan Minangkabau sesungguhnya. Muaranya adalah akan muncul pertanyaan jika perempuan di Minangkabau terklasifikasi, lantas bagaimana dengan laki-laki Minangkabau? Untuk menjawab pertanyaan ini bisa juga menjadi satu jurnal yang berujung pada pertanyaan terkait pembagian peran antara lakilaki dan perempuan di Minangkabau.

Stelsel matrilineal dengan sistem kehidupan yang komunal seperti yang dianut oleh suku bangsa Minangkabau, memosisikan perkawinan sebagai persoalan dan urusan kerabat, mulai dari mencari pasangan, membuat persetujuan, pertunangan dan perkawinan bahkan sampai kepada segala urusan akibat perkawinan itu sendiri. Sebab, perkawinan bukan masalah sepasang insan yang hendak membentuk keluarga atau rumah tangga saja. Oleh karena itu, falsafah Minangkabau telah menjadikan semua orang hidup bersama-sama, maka rumah tangga menjadi urusan bersama, termasuk masalah pribadi dalam hubungan suami istri.

Pola perkawinan orang Minangkabau bersifat eksogami. Kedua belah pihak atau salah satu pihak dari yang menikah itu tidak lebur ke dalam kaum kerabat pasangannya sehingga menurut struktur masyarakat Minangkabau setiap orang adalah warga kaum dan suku mereka masingmasing yang tidak dapat dialihkan. Jadi setiap orang tetap menjadi anggota kaumnya masing-masing (Navis, Alam; 193-194). Dengan demikian, tentu akan mempengaruhi pembagian peran antara laki-laki (suami) dengan perempuan (istri) dalam rumah tangga.

$\begin{array}{cc}\text { Dalam } & \text { rumah } \\ \text { masyarakat } & \text { Minangkabau, } \\ \text { pada }\end{array}$ dasarnya perempuan wajib menguasai ranah domestik, namun tidak pula menutup kemungkinan dia berada di ranah publik mengingat bahwa anak yang dilahirkan adalah menjadi anggota istri sehingga ayah tidak perlu bertanggung jawab terhadap kehidupan anak-anaknya karena anak-anaknya adalah urusan mamak (paman) kaumnya. Demikian juga ayah atau si laki-laki bertugas membiayai seluruh kebutuhan kemenakannya. Tak heran, pepatah Minang mengatakan: kaluak paku kacang balimbiang, daun pandang lenggang-lenggangkan, baok manurun ka saruaso, tanamlah siriah jo ureknyo. Anak dipangku kamanakan dibimbiang, rang kampuang dipatenggangkan, tenggang nagari jan binaso, tenggang sarato jo adatnyo.

\section{Dengan adanya perkawinan} eksogami di Minangkabau, memosisikan status istri sama dengan suaminya. Hal ini tidak terlepas dari stelsel matrilineal bahwa perempuan berkuasa penuh atas dirinya serta pola hidup komunal menyebabkan mereka tidak tergantung pada laki-laki atau suaminya. Sekalipun suami sangat dimanjakan di dalam rumah tangga, namun ia bukanlah pemegang tampuk kekuasaan terhadap anak dan istrinya.

Keperkasaan perempuan Minangkabau juga mempengaruhinya terkait pengambilan keputusan dalam keluarga. Karena perempuan di Minangkabau memiliki tampuk kekuasaan yang berefek kepada segala keputusan yang ada dalam rumah tangga harus diputuskan oleh perempuan, sebab perempuan adalah 
bundo kanduang; limpapeh rumah gadang. Suara perempuan didengar. Inilah unik dan istimewanya perempuan Minangkabau. Ia memiliki kedudukan dalam kaumnya. Termasuk dalam pola mengurus anak. Dalam adat Minangkabau, anak diurus oleh perempuan. Bahkan peran ayah dapat dikatakan hampir tidak ada. Kemudian keterlibatan perempuan dalam menyelesaikan segala persoalan yang ada dalam masyarakat dipegang oleh bundo kanduang yang berperan sebagai aktor intelektual di dalam menyelesaikan berbagai persoalan. Namun perlu diingat, sebagaimana yang telah dijelaskan di atas bahwa suara perempuan Minangkabau baru didengar ketika ia sudah menjadi istri atau ibu dan ketika sudah menjadi bundo kanduang, jika belum, perempuan Minangkabau masih mengekor pada aturan yang dibuat oleh laki-laki, lebih tepatnya mamak.

\section{E. Penutup}

Kedudukan tertinggi perempuan Minangkabau adalah bundo kanduang. Adanya bundo kanduang dalam suatu kaum karena kaum memerlukan seorang pemimpin perempuan yang dapat memimpin seluruh perempuan beserta anak cucu yang ada dalam kaum. Dengan demikian, setiap perempuan Minangkabau harus terdidik dan berpendidikan ibaratnya tau alua jo patuik, tau rantiang nan kamancucuak, alun takilek lah takalam. Ia adalah penentu segala macam keputusan di kaumnya. Termasuk dalam pengasuhan anak. Anak diasuh oleh perempuan, sedangkan laki-laki atau ayah dalam adat Minangkabau tidak begitu mendapat porsi yang besar karena dalam keluarga, anak juga turut menjadi tanggung jawab mamak: anak dipangku kamanakan dibimbiang. Ayah sebagai kepala keluarga hanya memiliki peran melindungi, mengayomi dan mencari nafkah saja, tetapi untuk membimbing adalah tugas mamak. Selanjutnya, perempuan dengan keistimewaannya disebut sebagai bundo kanduang adalah pemegang tampuk kekuasaan yang berperan sebagai aktor intelektual di dalam menyelesaikan berbagai persoalan di kaumnya maupun masyarakat pada umumnya. Jadi kedudukan perempuan Minangkabau dalam perspektif gender dalam hal ini seimbang. Artinya, laki-laki dan perempuan sama-sama berdaya sehingga perbedaan gender (gender differences) pun perbedaan jenis kelamin sosial tidak terlalu menjadi hambatan yang berarti bagi keberlangsungan hidup bermasyarakat. Meskipun secara kodrat laki-laki dan perempuan berbeda, namun secara gender mereka sama, sama-sama mempunyai peran dan tanggung jawab yang sama.

\section{Daftar Kepustakaan}

Borgatta, E.F dan Montgomery, R.J.V, Encyclopedia of Sociology ( New York: Macmillan Beauvoir, Simone de, Second Sex: Kehidupan Perempuan terj. Toni B. Febriantono dan 
Nuraini Juliasti (Yogyakarta: NarasiPustaka Promethea, 2016)

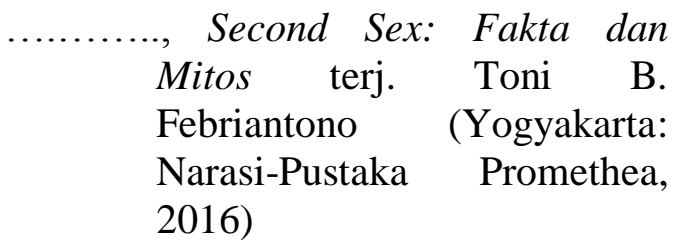

Diradjo, Ibrahim Dt. Sanggoeno, Tambo Alam Minangkabau: Tatanan Adat Warisan Nenen Moyang Orang Minang (Bukittinggi: Kristal Multimedia, 2009)

Fakih, Mansour, Analisis Gender dan Transformasi Sosial (Yogyakarta: Pustaka Pelajar, 2013)

Graham, "Making Difference" dalam Franzmann

Magazine,
"Woman and Religion", (2000)

Hornby, A.S, Oxford Advanced Learner's Dictionary (Oxford: University Press, 2012).

Meyerowitz, Joanne, "A History of Gender" dalam The American Historical Review, Vol 113, No 5, December, (USA: University of Chicago Press, 2008)

Navis, A.A, Alam Terkembang Jadi Guru: Adat dan Kebudayaan Minangkabau (Jakarta, 1982)

Ronkel, Ph.S. Van, "De invoering van ons Strafwetboek ter SWK naar aanteekeningen in een Maleische Handschrift", TBB. 46.(1994) 